\title{
Diálogos sobre a satisfação profissional no campo de Cuidados Paliativos Oncológicos: a voz do técnico de enfermagem
}

\author{
Dialogues on job satisfaction in the field of Palliative Oncology Care: the voice of the nursing technician \\ Diálogos sobre satisfacción laboral en el ámbito de los Cuidados Paliativos Oncológicos: la voz del técnico de enfermería
}

\begin{abstract}
RESUMO
Objetivo: Discutir sobre satisfação profissional no campo dos Cuidados Paliativos oncológicos, na visão dos técnicos de enfermagemde um hospital universitário do RJ. Método:Trata-se de um artigo original, sob a forma de um estudo qualitativo exploratório, desenvolvido a partir de uma categoria emergidaem pesquisa de mestrado, cuja técnica empregada foi a Projetiva,com avaliação das 10 entrevistas obtidaspela análise de conteúdo.Resultados: Foi unânime a insatisfação profissional, diante do desprestígio e a falta de incentivo para qualificação, da classe entrevistada, sobre Cuidados Paliativos e assistência na terminalidade da vida.Conclusão:Ressalta-se a importância dos setores de educação permanente e continuada proporcionarem, nas instituições de ensino e assistência, capacitações e aperfeiçoamento acerca das temáticas descritas, valorizando a participação dos técnicos de Enfermagem que operam o cuidado, bem com a inclusão dos mesmos como vozes ativas e essenciais nas discussões clínicas multiprofissionais sobre os pacientes assistidos.

DESCRITORES: Cuidados Paliativos na Terminalidade da Vida;Satisfação no Trabalho;Papel Técnico de Enfermagem;Qualificação Profissional

\section{ABSTRACT}

Objective: To discuss professional satisfaction in the field of palliative oncology care, in the view of nursing technicians at a university hospital in RJ. Method: This is an original article, in the form of a qualitative exploratory study, developed from a category that emerged in master's research, whose technique used was Projective, with an evaluation of the 10 interviews obtained through content analysis. Results: Professional dissatisfaction was unanimous, given the discredit and lack of incentive for qualification, of the interviewed class, about Palliative Care and assistance in the end of life. Conclusion: It is emphasized the importance of the sectors of permanent and continuous education to provide, in teaching and assistance institutions, training and improvement on the themes described, valuing the participation of Nursing technicians who operate the care, as well as the inclusion of them as active and essential voices in multiprofessional clinical discussions about assisted patients.
\end{abstract}

DESCRIPTORS: Palliative Care at the end of life;Job Satisfaction;Technical Nursing Role.Professional Qualification.

\section{RESUMEN}

discutir la satisfacción profesional en el campo de los cuidados oncológicos paliativos, a la vista de los técnicos de enfermería de un hospital universitario de RJ. Método: Se trata de un artículo original, en forma de estudio exploratorio cualitativo, desarrollado a partir de una categoría surgida en la investigación de maestría, cuya técnica utilizada fue Proyectiva, con una evaluación de las 10 entrevistas obtenidas mediante análisis de contenido. Resultados: La insatisfacción profesional fue unánime, dado el descrédito y falta de incentivo a la calificación, de la clase entrevistada, sobre los Cuidados Paliativos y la asistencia al final de la vida. Conclusión: Se enfatiza la importancia de los sectores de educación permanente y continua para brindar, en las instituciones de enseñanza y asistencia, capacitación y mejora en los temas descritos, valorando la participación de los técnicos de Enfermería que operan el cuidado, así como la inclusión de los mismos como voces activas y esenciales en discusiones clínicas multiprofesionales sobre pacientes asistidos.

DESCRIPTORES: Cuidados Paliativos al final de la vida;Satisfacción Laboral;Rol Técnico de enfermería; Calificación Profesional.

RECEBIDO EM: 17/05/2021 APROVADO EM: 30/08/2021 


\section{artigo}

Souza, S. V. F, Koifman, L.

Diálogos sobre a satisfação profissional no campo de Cuidados Paliativos Oncológicos: a voz do técnico de enfermagem

\section{SAMHIRA VIEIRA FRANCO DE SOUZA}

Enfermeira staff do CTI Pediátrico do INCA e docente de Enfermagem da FAETEC; Mestre pelo Instituto de Saúde Coletiva da UFF

ORCID: 0000-0001-6942-6833

\section{LILIAN KOIFMAN}

Professora Titular do Instituto de Saúde Coletiva da UFF; Doutora em Saúde Pública ENSP / FIOCRUZ. ORCID: 0000-0003-1038-3490

\section{INTRODUÇÃO}

A satisfação no trabalho é determinada pela comparação das expectativas sobre o trabalho e sua experiência real, relacionando-se com as crenças e emoções que os indivíduos têm em relação ao seu trabalho. Um profissional satisfeito torna seu local de trabalho a extensão do seu lar, movimentando energias positivas, fortalecendo vínculos e tornando o ambiente produtivo, objetivando bons resultados e superando as metas institucionais estabelecidas.

O serviço de saúde em meio a uma pandemia tem se mostrado crucial, sendo assim, as estratégias do cuidado integral (biopsicossocial) entre os profissionais para combater a precarização do cuidado em saúde se tornam imprescindíveis para o avanço da Enfermagem. Em tempos da COVID-19, onde a notoriedade e protagonismo da Enfermagem encontram-se em evidência, conforme observado nas mídias sociais, torna-se necessário dialogar sobre o status dessa classe profissional fora deste cenário, onde o status de desvalorização é crônico e latente nos diferentes espaços de atuação , evidenciadas pela baixa remuneração e pela falta de incentivo para capacitações e qualificações nas instituiçōes de saúde.

A precarização dos processos de trabalho e oferta de salários irrisórios, tanto em instituições privadas quanto em processos seletivos públicos, gera uma série de transtornos para esses profissionais, impactando na qualidade da assistência prestada à população. A baixa remuneração, a sobrecarga de trabalho, a falta de autonomia e de reconhecimento social contribuem para o surgimento de alterações psíquicas, acarretando desmotivação para o cuidado e para contribuições voltadas para as melhorias
Um profissional

satisfeito torna seu

local de trabalho

a extensão do seu

lar, movimentando

energias positivas,

fortalecendo

vínculos e tornando

o ambiente

produtivo,

objetivando

bons resultados

e superando as

metas institucionais estabelecidas institucionais, diante da ideia de que seu trabalho éirrelevante e sem valor.

Cabe ressaltara exigência, cada vez mais intensa e expansiva, relativa à responsabilidade do profissional de Enfermagem para com seus pacientes, acumulando no seu hall de atribuições preocupações físicas, morais, sociais e emocionais, mesmo diante da conotação de desprestígio desse profissional na organização de saúde. Aditado a este fato,um ambiente com relações interpessoais segregadas e sem incentivo da instituição para desenvolvimento de competências e habilidades, torna o ambiente inóspito e improdutivo, além de contribuir para solicitaçōes de licenças médicas e defasagem do quantitativo da equipe.

Em estudo realizado com representantes dessa classe, foram destacados como relevantes para o cenário de desmotivação, em intensidade produtora de desordens mentais e mudança de atividade laboral, a ausência de comunicação, a dificuldade em criar vínculos, hierarquização no processo do cuidado e não cooperação entre pares, resultando em uma assistência precária e fragmentada.

Segundo o Conselho Federal de Enfermagem (COFEN), órgão que normatiza e fiscaliza o exercício do profissional de Enfermagem, sabe-se que, no Brasil, a Enfermagem absorve a maior fração do cuidado em saúde. A força de trabalho de Enfermagem integra uma equipe multiprofissional e interdisciplinar, abarcando diferentes categorias com competências distintas em seu núcleo. Enfermeiros, técnicos e auxiliares de Enfermagem representam, no Brasil, $80 \%$ da força de trabalho em saúde. Em hospitais, estima-se que os trabalhadores de Enfermagem sejam $60 \%$ da força do trabalho total.

Conforme Boff, o cuidado humano não se trata de nossas intervençōes profissionais 
de saúde sobre um objeto e sim mediante a relação sujeito-sujeito. $\mathrm{O}$ autor prossegue dizendo que a "relação do cuidado não é de domínio sobre, mas sim de convivência; não é pura intervenção, mas sim interação". Desta forma, a atividade executada por estes trabalhadores é essencial para os serviços de saúde e de extrema responsabilidade e complexidade, em todos os níveis de atenção em saúde e perspectivas de cuidado, inclusive dos Cuidados Paliativos.

Sob essa ótica, tendo em vista que nas últimas décadas pesquisas que fomentem a reestruturação curricular vêm alcançando destaque, realizou-se um estudo que avaliou o caráter prático-pedagógico, no processo formativo e de trabalho, dos técnicos de enfermagem, acerca da terminalidade da vida e os cuidados paliativos. Nas categorias elaboradas com base nas entrevistas obtidas, emergiu uma categoria que trata sobre a desmotivação profissional para qualificação em Cuidados paliativos e descontentamento com o status do técnico na equipe multiprofissional, sendo esta discussão o objeto deste artigo.

Com base no retorno obtido na pesquisa descrita, o presente estudo justifica-se diante da lacunas existentes na formação em saúde a respeito da morte e os cuidados paliativos, quiçá quando esta investigação direciona-se a profissionais de saúde de nível técnico, profissionais estes com baixa visibilidade e prestígio no cenário social e de saúde.

A área de oncologia é carregada de peculiaridades que, frequentemente, são desconhecidas pelo profissional enfermeiro que não possui formação específica na área no decorrer do ensino superior. Isso se deve ao fato de que, na maior parte das instituições de ensino brasileiras, não é abordado o ensino da oncologiaao longo do curso de graduação em enfermagem8. Na educação profissionalizante em saúde tal cenário agrava-se ainda mais, gerando mais um fator estressante para o profissional que atua nesse campo. Tanto por falta de expertise, quanto pelo fato de lidar com pacientes fora de possibilidade terapêutica, com a ameaça da morte mais próxima e real ao seu campo de atuação.

\section{A precarização}

dos processos

de trabalho e

oferta de salários

irrisórios, tanto em

instituições privadas

quanto em processos

seletivos públicos,

gera uma série de

transtornos para

esses profissionais,

impactando na

qualidade da

assistência prestada

à população
Diante de falas tão marcantes e unânimes, coletadas durante a realização do campo de pesquisa de mestrado, a autora foi instigada a desenvolver este artigo, cujo objetivo é discutir sobre a satisfação profissional no campo dos Cuidados paliativos oncológico, sob a visão dos técnicos de enfermagem, lotados no serviço de oncologia de um hospital universitário do RJ.

\section{MÉTODO}

Trata-se da elaboração de um escrito no modelo de artigo original, que toma por base o material exposto em uma dissertação de mestrado defendida em 2019, sob a forma de uma Pesquisa Qualitativa Exploratória. A técnica de entrevista empregada foi a Técnica Projetiva com objetivo de captar percepções e concepções que normalmente não são ditas quando adotados instrumentos de coleta de dados tradicionais.

A partir de uma projeção que tratava sobre a morte reproduzida em diferentes perspectivas cinematográficas, com o auxílio de um roteiro de entrevista que contivesse questões relativas ao ensino, prática e vivência, iniciava-se a abordagem dos participantes, deixando seu discurso livre para abarcar os objetivos da pesquisa e outros apontamentos relevantes.

A pesquisa foi realizada entre Agosto e Outubro de 2018, em um Hospital Universitário da região metropolitana do Rio de Janeiro, considerada como uma Unidade de Assistência de Alta Complexidade em Oncologia (UNACON), com 10 técnicos de Enfermagem do serviço de oncologia, sendo submetido à aprovação do Comitê de Ética em Pesquisa do Hospital Universitário Antônio Pedro da Universidade Federal Fluminense (UFF). Por se tratar de pesquisa em seres humanos, seguiu as Normas Regulamentadoras de Pesquisa envolvendo Seres Humanos (Resolução CNS n ${ }^{\circ}$ 466/ 2012)9. Esta submissão ocorreu em Março de 2018 e aprovada ao final de Maio de 2018, sendo comprovada pela CAAE: 87431618.5.0000.5243, versão 2, Parecer $\mathrm{n}^{\circ} 2.680 .108$, após anuência do referido Hospital.

Critérios de inclusão dos participantes: 


\section{artigo}

Souza, S. V. F, Koifman, L.

Diálogos sobre a satisfação profissional no campo de Cuidados Paliativos Oncológicos: a voz do técnico de enfermagem

Profissional técnico de enfermagem com registro ativo no COREN (Conselho Regional de Enfermagem); Fazer parte do quadro de funcionários do hospital, seja como contrato temporário ou estatutário, sem estar licenciado ou de férias. Critérios de exclusão dos participantes: Profissional técnico de Enfermagem licenciado ou em vigência de férias, no período da coleta; Profissional que atue como enfermeiro no hospital, cenário da coleta, mas atue como técnico de Enfermagem em outro vínculo empregatício; Estudantes do curso profissionalizante de enfermagem, em processo formativo, estagiários na instituição hospitalar ou profissionais com vínculo de auxiliares de Enfermagem, mesmo que com graduação técnica.

Todos os participantes assinaram um Termo de Consentimento Livre e Esclarecido - TCLE(conforme Resolução $\mathrm{n}^{\circ}$ 510/2016), garantindo o anonimato e imparcialidade do estudo, com sigilo das informações obtidas através da entrevista. Para que não haja qualquer menção que colabore para sua identificação, nos referimos ao entrevistado através de uma espécie de borboleta, símbolo dos Cuidados Paliativos.

Dentre os apontamentos obtidos, transformados em 4 categorias e 8 subcategorias através da Análise de Conteúdo das entrevistas, destaca-se o tema central para desenvolvimento deste artigo: Desmotivação profissional para qualificação com vistas à melhoria assistencial ao paciente Fora de Possibilidade Terapêutica.

\section{RESULTADOS}

Categoria: Desmotivação profissional para qualificação com vistas à melhoria assistencial ao paciente Fora de Possibilidade Terapêutica.

A sobrecarga profissional, o déficit de recursos humanos e o sofrimento psíquico $\mathrm{e}$ moral, vivenciado pela equipe de Enfermagem no cuidado humano, configuram-se como fontes desmotivadoras no seu campo de atuação. Esta desmotivação repercute na qualidade assistencial, no afastamento produzido nas relações humanas, bem como em adoecimento mental e físico.

Quando estudamos esse sentimento voltado para o cuidado na terminalidade da vida temos o aumento exponencial da carga de sofrimento imputada pelo medo da perda e autoconscientização da finitude humana. Conforme Simoni e Santos, no trabalho hospitalar em cuidados paliativos, as profissionais convivem com a solidão, o medo da loucura e do adoecimento físico pela mobilização emocional e física que as histórias dos pacientes suscitam mesmo fora do ambiente hospitalar. Grande carga emocional e desgaste subsequente são repercussões geradas no desempenho de incumbências relacionadas ao sofrimento e à morte, resultando em relações fragmentadas e no desejo de abandono da profissão.

A dificuldade do profissional de saúde em se deparar com a morte, incipiente abordagem na formação sobre conteúdos essenciais para teoria e prática, somados à falta de incentivo para qualificação nos locais de trabalhos, tornam-se responsáveis pelo sentimento de desalento e tristeza que pairam sobre os trabalhadores, motivando-os a procurarem outras atividades laborais, como demonstrado a seguir:

\section{da finitude humana}


procedimentos técnicos, sem análise crítica e embasamento científico.

"Eu me sinto uma "limpadora, trocadora de fralda" porque você vive no automático sem te incentivarem a refletir o porquê isso. Não é só aqui, mas sim em tudo quanto é lugar. Você é técnico de Enfermagem e só serve para limpar. Eu quero aprender e participar" (Borboleta Rabo de Andorinha).

"Ah o técnico não sabe de nada (como falam)... como assim eu não sei? Sei até a dose. Tanto eu sei que quem vai preparar $e$ administrar sou eu. Como fala assim? A gente sabe porque prepara $e$ administra. Uma vírgula errada, você vai olhar e reconhecer. $O$ erro foi onde? Mas eu vou lá sinalizo e ele corrige. Tudo bem que eles nem agradecem, mas fui lá e fiz a minha parte. Essa falta de valorização do técnico as vezes me dá uma certa desmotivada. A gente não é valorizado, só sabem cobrar, mas também não sabem explicar, ensinar, orientar, entendeu?" (Borboleta Greta Ouro).

"Eu acho que os gestores tinham que pensar um pouco no técnico de Enfermagem. Orientar mais esse técnico, valorizar mais esse técnico, porque é ele que vai passar pro enfermeiro o que você tá vendo no paciente. Se você não souber ensinar ele, como ele vai te passar [informação]?" (Borboleta Greta Ouro).

"Eu acho importante, inclusive os rounds não serem lá dentro [sala de reunião] e incluir os técnicos. Poder pegar um ou outro profissional e explicar sobre o quadro clínico do paciente. Pegar e perguntar, você sabe o que é Linfoma? Mieloma? Você trata muitas vezes do paciente e tem que aprender tudo pela internet" (Borboleta Esmeralda).
"Eu gosto de contribuir, conversando com o profissional que esteja envolvido no momento.Acho importante a gente participar (...) participar dos rounds, quando o médico e o enfermeiro transmitem informaçóes importantes do paciente para melhor cuidar" (Borboleta Morpho Azul).

"Quanto a incentivo da instituição para abordar questóes inerentes à morte, luto e cuidados paliativos não vejo incentivo nem para paciente, familiar, muito menos para o profissional, para quem está ali na ponta" (Borboleta Coruja).

"Com certeza é muito voltado para nivel superior. Até porque a gente não sabe. Aqui então no ambulatório pouca gente sabe dos cursos; quase não chegam até nós, não sei o porquê; se eles cortam pra gente não sair do setor por ter poucos profissionais; muito pouco. Sobre esse cuidado paliativo raramente, acho que deve ter tido um ou outro aí, mas a gente não participou não" (Borboleta Flambeau).

Uma base formativa deficiente, somada ao fato de não haver suporte no local de trabalho, através de capacitações e atualizações, fragiliza o complexo prestador do cuidado humano, limitando as trocas entre profissional-paciente, além de engessar essa relação com uma comunicação superficial, como observado no discurso a seguir.

“(...)Porque as primeiras vezes que cuidei de paciente terminal eu não tinha tanto o que falar, abordar para cuidar porque gerava um bloqueio. Até para dar um bom dia, porque você sabe que ele não terá um bom dia. Acho que se o técnico fosse preparado para quando saisse do curso e até para encarar o estágio ele já saberia passar mais tranquilidade para o paciente, saberia como conversar, sem agir no auto- mático" (Borboleta Morpho Azul).

"Paciente bematológico aqui pra mim é muito complicado, principalmente que aqui eles não explicaram muito pra gente como era o perfil desse paciente. Então, a gente teve que entrar sim e viver a situação para aprendermos sozinhos" (Borboleta Greta Ouro).

\section{DISCUSSÃO}

A não valorização do status do técnico de Enfermagem acaba sendo extensiva ao incluí-los numericamente como integrantes de uma equipe multiprofissional, porém sem conferi-los a importância devida. Desta forma, há o desprestígio deste profissional na tomada de decisão e na participação de discussões para o cuidado em saúde, como evidenciado a seguir:

Os rounds multiprofissionais e interdisciplinares tendem a enriquecer as discussões e valorizar todos os integrantes da equipe que prestam cuidado. Conforme Gianinina, as reuniões em grupo sistematizadas devem ampliar seu conteúdo, não limitando em técnicas de procedimentos, promovendo discussões a fim de somar esforços. Sob esta lógica, todos contribuem e considera-se a premência de satisfação das necessidades emergentes dos pacientes na terminalidade da vida.

Um aspecto concernente a esta categoria, diz respeito à hegemonia médica e ao status hierárquico ocupado por esta classe. Trata-se de uma questão cultural da valorização médica em detrimento das demais classes profissionais, conferindo-se atenção unilateral para o poder decisório. Esta discussão envolvendo escolarização, maior renda diante do status profissional e posição social, são questões discutidas por Pierre Bourdieu acerca do Capital Simbólico.

Outra questão bastante sinalizada pelos entrevistados diz respeito à falta de incentivo institucional à educação continuada e permanente sobre Cuidados Paliativos e terminalidade da vida. Como já citado no decorrer deste artigo, o déficit de recursos humanos torna-se um fator limitante à 


\section{A segregação das \\ categorias de saúde}

e a falta de incentivo

para ampliar

conhecimentos

científicos acarreta

atuações superficiais

e limitadas, não

ratificadores do

potencial técnico

e agregador desta

classe profissional extensão dos cursos de atualização e capacitação na instituição para os técnicos de Enfermagem, não gerando liberação para estudo. Esta atitude por parte dos gestores e líderes setoriais gera intensa insatisfação por parte dos profissionais, configurando-se como um fator de risco para sobrecarga emocional e física.

A falta de incentivo para participação em fóruns, simpósios, cursos, congressos, principalmente aqueles voltados para a Tanatologia, como estudo do processo de morrer e da morte e os Cuidados Paliativos, pode ser responsável pela ausência de reflexão crítica e tecnicamente competente reproduzida nos espaços de saúde, principalmente por profissionais de nível técnico, contribuindo para seu desprestígio social.

Sendo assim, limita a participação desses profissionais nos campos de discussão acerca desses temas, perpetuando a "invisibilidade social" dessa classe profissional, dentro do sistema de saúde e no âmbito acadêmico, bem como contribuindo para as iatrogenias acometidas por escassez de conhecimento científico.

Kóvacs resume bem a exaustão e a impotência do profissional de enfermagem ao lidar com a morte no seu cotidiano e com as demandas advindas dessa possibilidade, demonstrando seu protagonismo nas relações construídas: A equipe de Enfermagem apresenta alto índice de colapso pela sua função de cuidado diário aos pacientes, portanto em contato mais intenso com a dor e sofrimento. São também estes profissionais, que os pacientes buscam para falar de suas questões íntimas, levando a situações constrangedoras pelo fato de não terem resposta a todas questões e pela eclosão de sentimentos internos (...). Os pacientes por sua vez, buscam respostas, querendo confirmação de sua esperança, e, em razão destas demandas, podem sobrecarregar ainda mais a equipe, que já conta com uma intensa quantidade de funções a desempenhar.

Todas as narrativas supracitadas demonstram o quanto a invisibilidade do sujeito desta pesquisa afeta a coesão no trabalho multiprofissional, favorecendo a não satisfação em permanecer na profissão e executar suas atividades, mesmo com o autorreconhecimento do técnico de Enfermagem acerca da sua essencialidade na arte do cuidar. A segregação das categorias de saúde e a falta de incentivo para ampliar conhecimentos científicos acarreta atuações superficiais e limitadas, não ratificadores do potencial técnico e agregador desta classe profissional.

\section{CONCLUSÃO}

Seja desde a sobrecarga de trabalho, pelo déficit de trabalhadores em saúde, que impossibilite a liberação desses profissionais para cursos de capacitação e afins acerca da temática, quanto a não agregação dos mesmos para participação de discussôes clínicas e tomada de decisão, a questão da desvalorização dessa categoria necessita ser analisada urgentemente.

Ressalta-se, também, a importância dos espaços de Educação permanente e continuada proporcionarem, nas instituições de ensino e assistência, capacitações e aperfeiçoamento acerca das temáticas, valorizando a participação dos técnicos de Enfermagem que operam o cuidado, diretamente e em maior tempo, ao paciente. Ao aumentarmos a valorização e ampliarmos a construção de espaços formativos para os mesmos, vislumbrando tais discussões como ações pedagógicas, contribuiremos para a mudança da generalizada desmotivação profissional da classe, constatada nesta pesquisa, bem com a inclusão dos mesmos como vozes ativas e essenciais nas discussões clínicas multiprofissionais sobre os pacientes assistidos, sem menoscabar a importância destes profissionais no cuidado humano. 


\section{REFERÊNCIAS}

1. Lorber M, Skela Savič B. Job satisfaction of nurses and identifying factors of job satisfaction in Slovenian Hospitals. Croat Med J. 2012 Jun;53(3):263-70. doi: 10.3325/cmj.2012.53.263. PMID: 22661140; PMCID: PMC3368291.

2. Botelho, J.L.S.; Santos, S.M.; Aquino, C.F.; Melo, J.M.O.; Freiras, I.G.C.;Como melhorar a qualidade da saúde da equipe de enfermagem mediante ao COVID-19. DOI: https://doi.org/10.36489/ saudecoletiva.2021v11164p5680-5689.

3. Sá, Adriana Müller Saleme de, Martins-Silva, Priscilla de OIiveira, \& Funchal, Bruno. (2014). Burnout: o impacto da satisfação no trabalho em profissionais de enfermagem. Psicologia \& Sociedade, 26(3), 664-674. https://doi.org/10.1590/S010271822014000300015 .

4. Ferro Denise, Zacharias Fabiana Costa Machado, Fabriz Luciana Aparecida, Schonholzer Tatiele Estefâni, Valente Silvia Helena, Barbosa Sara Maria et al. Absenteísmo na equipe de enfermagem em serviços de emergência: implicações na assistência. Acta paul. enferm. [Internet]. 2018 Jul [citado 2021 Abr 07] ; 31( 4):399408.http://www.scielo.br/scielo.php?script=sci_arttext\&pid=S01032100.https://doi.org/10.1590/19820194201800056.

5. Paparelli R, Sato L, Oliveira F. A Saúde Mental relacionada ao trabalho e os desafios aos profissionais da saúde. Rev Bras Saúde Ocup. 2011;36(123):118-27. http://dx.doi.org/10.1590/ S0303-76572011000100011.

6. Conselho Federal de Enfermagem. Pesquisa inédita traça perfil da enfermagem. Disponivel em: <http://novo.portalcofen. gov.br/pesquisa-inedita-traca-perfil-da-enfermagem_31258. html>. Acesso em: 04 abril. 2021.

7. Boff, Leonardo . Saber cuidar: ética do humano, compaixão pela terra. 6. ed. Petrópolis: Vozes; 1999.

8. Rodrigues AB, Chaves EC, Fatores Estressantes e Estratégias de Coping dos Enfermeiros atuantes em Oncologia; Rev Latino-am Enfermagem 2008. Disponivel em: http://www.scielo.br/ pdf/rlae/v16n1/pt_03.pdf. Acesso em 06 Abril 2021 01:44.

9. Brasil. Conselho Nacional de Saúde. Resolução 466/12. Trata de pesquisas em seres humanos e atualiza a resolução 196. [Internet]. Diário Oficial da União. 12 dez. 2012 (acesso 13 fev 2021).

10. Simoni, Miguel de, Santos, Mônica Loureiro dos. Considerações sobre cuidado paliativo e trabalho hospitalar: uma abordagem plural sobre 0 processo de trabalho de enfermagem. Psicologia USP, 2003,14(2), 169-194;https://doi.org/10.1590/ S0103-65642003000200009.

11. Fernandes, Priscila Valverde, Iglesias, Alexandra, Avellar, Luziane Zacché. $O$ técnico de enfermagem diante da morte: concepções de morte para técnicos de enfermagem em oncologia e suas implicações na rotina de trabalho e na vida cotidiana. Psicologia: teoria e prática,2009,11(1), 142-152.

12. Gianinia, M. Equipe de Enfermagem diante da morte. Revista Escola Enfermagem, 2009, São Paulo, 32(2), 117-123.

13. Bourdier, P. O campo científico. In: ORTZ, Renato (Org.). São Paulo: Ática, 1994.
14. Assumpção, Evaldo. Biotanatologia e bioética. São Paulo: Paulinas, 2005.

15. Kovács, Maria Julia.Educação para a morte. Psicologia: Ciência e Profissão, 2005, 25(3), 484-497. https://dx.doi.org/10.1590/ S1414-98932005000300012. 